\title{
Determination of Free Glycerol in Biodiesel
}

\author{
Martin Hájek, František Skopal, Jaroslav Machek \\ Department of Physical Chemistry, Faculty of Chemical Technology, \\ University of Pardubice, Czech Republic
}

Correspondence: Martin Hájek, Department of Physical Chemistry, Faculty of Chemical Technology, University of Pardubice, nám Čs. legií 565, 53210 Pardubice, Czech Republic. Phone: +420 466037 047, Fax: +420 466037 068; e-mail: hajek.martin@centrum.cz

Keywords: Analytical method, biodiesel, glycerol, HPLC, extraction 


\section{Summary}

Within the biodiesel production process, glycerol arises as a side product. This free glycerol is included also in biodiesel in a small amount. Several methods are known to determine it. Some of them are based on the GC. In this paper a new method is introduced, which is based on the extraction of free glycerol into water and its subsequent determination in water solution by HPLC with refractometric detection. The comparison of GC and HPLC methods led to the same results. The new method is reliable and comparatively fast for determination of free glycerol in biodiesel.

\section{Introduction}

Mixture of alkylesters of higher fatty acids (biodiesel) arises within transesterification (alcoholysis) of vegetable oils. Glycerol is created during the biodiesel production process as a side product. After separation of glycerol phase, an imperceptible amount of free glycerol remains in biodiesel. Its maximum permissible concentration $0.02 \mathrm{w} \%$ is set by the European norm EN 14214:2003. The same maximum value is given for the ASTM specification. Therefore it is necessary to determine the amount of free glycerol in biodiesel. Several methods of free glycerol determination were already described: Photometric determination based on enzymatic reaction [1]. Photometric determination based on periodate oxidation of glycerol [2]. GC method without extraction and derivatization of the sample; this method has insufficient detection limit [3]. GC methods using extraction of glycerol from biodiesel into water or its derivatization with the use of capillary column with FID or MS detector [4]. GC method with capillary column using derivatization of free glycerol by trimethylchlorsilan was developed and flame ionization was used as detector [5]. A HPLC method with pulsed amperometric detection and $0.5 \mathrm{~mol} / 1$ sodium chloride aqueous solutions as eluant was developed. Extraction of glycerol from biodiesel into water and hexane is used in this method [6]. Iodometric determination of glycerol [7], this method needs large amount of sample and has low sensitivity.

It is generally known and industrially widely used that glycerol can be extracted from biodiesel by water. In our new method, free glycerol is extracted from biodiesel into small amount of water, this solution is concentrated, glycerol in it is separated by HPLC and determined refractometrically.

\section{Materials and methods}

\subsection{Used chemical}

Glycerol (99.5\%), Lachema-Neratovice, Czech Republic 


\subsection{Preparation of samples}

\subsubsection{Apparatus}

The glass apparatus for extraction of glycerol from biodiesel into water, separation of the resulting aqueous glycerol solution and its concentration is displayed at Fig. 1. It consisted of a bulb (volume $50 \mathrm{ml}$ ) with a calibrated cylinder (volume $5 \mathrm{ml}$ ) in the bottom part. Stirring was executed by bubbling of air through the ground-glass joint capillary immersed into the mixture of biodiesel and water with the help of a water pump. A stopcock for stirring regulation was attached to the upper part of the capillary. Concentration process was conducted at low pressure and higher temperature. Heating-up of the mixture was carried out by immersing of the apparatus into the hot water bath. The lowered pressure was regulated by the stopcock on the capillary.

\subsubsection{Procedure}

A known amount of biodiesel (4-20 g) was put into the apparatus. Then approximately $4.5 \mathrm{ml}$ of distilled water was added. The capillary was inserted in the apparatus and subsequently the water pump was initiated. The extraction was finished approximately after 30 minutes of stirring. After two hours total separation of water phase from biodiesel phase took place. Then the upper biodiesel phase was sucked away. The water phase, with extracted glycerol, was evaporated by vacuum under stirring described above to $0.5-1 \mathrm{ml}$. Then the volume of this concentrate was measured in the calibrated cylinder. Such sample was used for further HPLC analysis.

\subsection{HPLC analysis of samples}

High pressure liquid chromatograph (LCP 4000.1 Ecom spol. s r.o.) with refractometric detector (RIDK 120, Laboratorní přistroje Praha, Czech Republic) was used to determine the concentration of free glycerol in the sample. Determination was performed on Separon TM SGX column with particle $7 \mu \mathrm{m}$ (901-300004). Deaerated demineralized water was used as mobile phase (flow $0.5 \mathrm{ml} / \mathrm{min}$ ). The resulting chromatogram was measured in a PC and evaluated by the CSW v 1.0 program. Two peaks were observed in the chromatogram, the first one had retention time 0.9 min, the second one $1.36 \mathrm{~min}$. According to used standards, the first peak corresponds to trans of soaps (i.e. potassium salts of fatty acids of rape oil extracted from biodiesel) and the second one is glycerol. The chromatogram is shown in Fig. 2.

To determine the amount of glycerol in the samples, the calibration curve of water solution of glycerol from 0.01 to $3 \mathrm{w} \%$ was measured (Fig. 3). Concentration $0.0004 \mathrm{w} \%$ was determined as detection limit in water solution of the prepared concentrate. The minimum detectable amount of free glycerol in biodiesel is very low (60 ppm) when the maximum amount of biodiesel (cca $25 \mathrm{~g}$ ) for determination is used. The standard solutions could be kept in the refrigerator for two months, 
after which the concentration decreased. The resulting concentration of free glycerol in biodiesel was determined through this equation:

$$
w_{G}=\frac{\left(A-{ }^{\prime}\right) \cdot V_{\text {water }}}{k \cdot m_{B D}}
$$

$\begin{array}{ll}w_{G} & \text { weight percent of free glycerol in biodiesel }[\mathrm{w} \%] \\ A & \text { peak area of glycerol in chromatogram } \\ q & \text { intercept of calibration curve } \\ k & \text { slope of calibration curve } \\ V_{\text {water }} & \text { total volume of the concentrate }[\mathrm{ml}] \\ m_{B D} & \text { amount of the analyzed sample of biodiesel }[\mathrm{g}]\end{array}$

\subsection{Referential comparative GC determination}

As a comparing method, free glycerol in some samples was determined by GC method. Gas chromatograph CHROM 5, Laboratorní přístroje Praha, Czech Republic and column 1200x3 mm filled with Tenax TA were used. The carrier gas was helium with flow $36 \mathrm{ml} / \mathrm{min}$. Injected volume was $1 \mu \mathrm{l}$. Glycerol was detected by flame-ionization detector (FID). Temperature of injection, on column and on detector was 290,210 and $190^{\circ} \mathrm{C}$, respectively. The chromatogram was measured by PC and evaluated by CSW v 1.0 program. One peak with retention time 2.9 min was observed in the chromatogram. The concentration of free glycerol in the sample was determined by means of the calibration curve. Aqueous solutions with concentrations from 0.01 to $0.2 \mathrm{w} \%$ of glycerol were used as standards.

\section{Results and discussion}

\subsection{Apparatus test}

Apparatus for sample preparation (see 2.2) was tested on these criteria:

A.) Degradation and evaporation of glycerol during the extraction and concentration process

B.) Quantity of glycerol extraction from biodiesel in one step

Ad A.) A known amount of aqueous glycerol solution with known composition was given into the apparatus and concentrated subsequently as described in 2.2. Then the concentration of glycerol was determined by HPLC. In Table 1 the given and determined glycerol concentrations of tree samples are compared. The results are practically equal, small differences are probably caused by inaccuracy in the determination of the sample volume after concentration and by the chromatographic analysis. Consequently, glycerol does not neither degrade nor evaporate. 
Ad B.) A sample of biodiesel was extracted by water in the apparatus as described in 2.2. Then, the biodiesel phase was sucked away and extracted again. The concentrations of free glycerol in biodiesel after first and second extraction step in $\mathrm{w} \%$ are introduced in Table 2. After second extraction, the concentration of free glycerol is already negligible; the values are on the detection limit. Therefore it is obvious that one extraction step is sufficient and practically whole amount of glycerol is transported from biodiesel into the water phase.

\subsection{Comparison of results of GC and HPLC method}

As the comparing method, GC (see 2.4) was used; the results of this method are considered reliable. Three samples of methylester were prepared from rape seed oil by the method according to [8]. These three samples of aqueous glycerol concentrate from three various biodiesel species were prepared in described way (see 2.2) and analyzed on the content of free glycerol by both chromatographic methods. The analysis was repeated four times on both HPLC and GC to calculate the standard deviation. Table 3 shows that both methods led to practically identical results.

\section{Conclusion}

Determination of free glycerol in biodiesel is important, because it is one of the indicators of biodiesel quality. Its maximum concentration is given by the Euro norm.

A new method for its determination by HPLC was tested and compared with the known GC method. It was verified that both methods give almost the same results. Both methods are considered suitable and exact enough to analyze free glycerol in biodiesel. An aqueous glycerol concentrate must be prepared to the own HPLC or GC analysis. It is realized by one step water extraction of biodiesel sample, separation of biodiesel and water phases and partial water evaporation of the water phase in the described apparatus under described conditions. No decomposition and evaporation of glycerol was found out during concentration process. The new HPLC method is reliable, fast and environmentally friendly. Determination has very low detection limit of free glycerol in biodiesel $(60 \mathrm{ppm})$, which is more than hundred times lower than the maximum amount set by the European norm. Complete analysis takes approximately 3 hours, including preparation of the sample.

\section{Acknowledgements}

This work has been funded by the research project MŠM 0021627502 of Czech Ministry Youth and Sport.

\section{Reference}

[1] J. Bailer and K. de Hueber: Determination of saponifiable glycerol in biodiesel. Fraenius J. Anal. Chem. 1991, 340, 186. 
[2] P. Bondioli and L. Della Bella: An alternative spectrofotometric method for the determination of free glycerol in biodiesel. Eur. J. Lipid Sci. Technol. 2005, 107, 153-157.

[3] P. Bondioli, C. Mariani, A. Lanzani, E. Fedeli, S. Veronese: Vegetable oil derivatives as diesel fuel substitutes. Analytical aspects. Note 2: Determination of free glycerol. Riv. Ital. Sostanze Grosse. 1992, 69, 7-9.

[4] M. Mittelbach: Diesel fuel derived from vegetable oils V: gas chromatographic determination of free glycerol in transesterified vegetable oils. Chromatographia. 1993, 37, 623.

[5] Ch. Plank, E. Lorbeer: Simultaneous determination of glycerol, and mono-, di- and triglycerides in vegetable oil methyl esters by capillary gas chromatography. Journal of Chromatography A. 1995, 697(1-2), 461-468.

[6] P. Lozano, N. Chiran, J. Graille, D. Pioch: Measurement of Free Glycerol in Biofuels. Fresenius J. Anal. Chem. 1996, 354, 319-322.

[7] M. Jureček: Organická analysa II. ČSAV Praha (the Czech Republic) 1957.

[8] F. Skopal, K. Komers, J. Machek, I. Koropecký: the Czech Republic Patent 289417 (2001) 


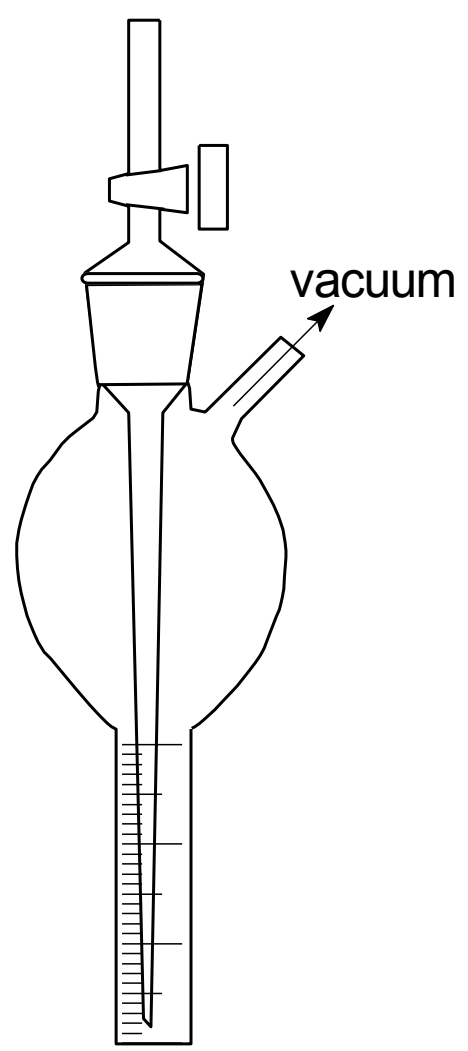

Fig. 1, Hájek 


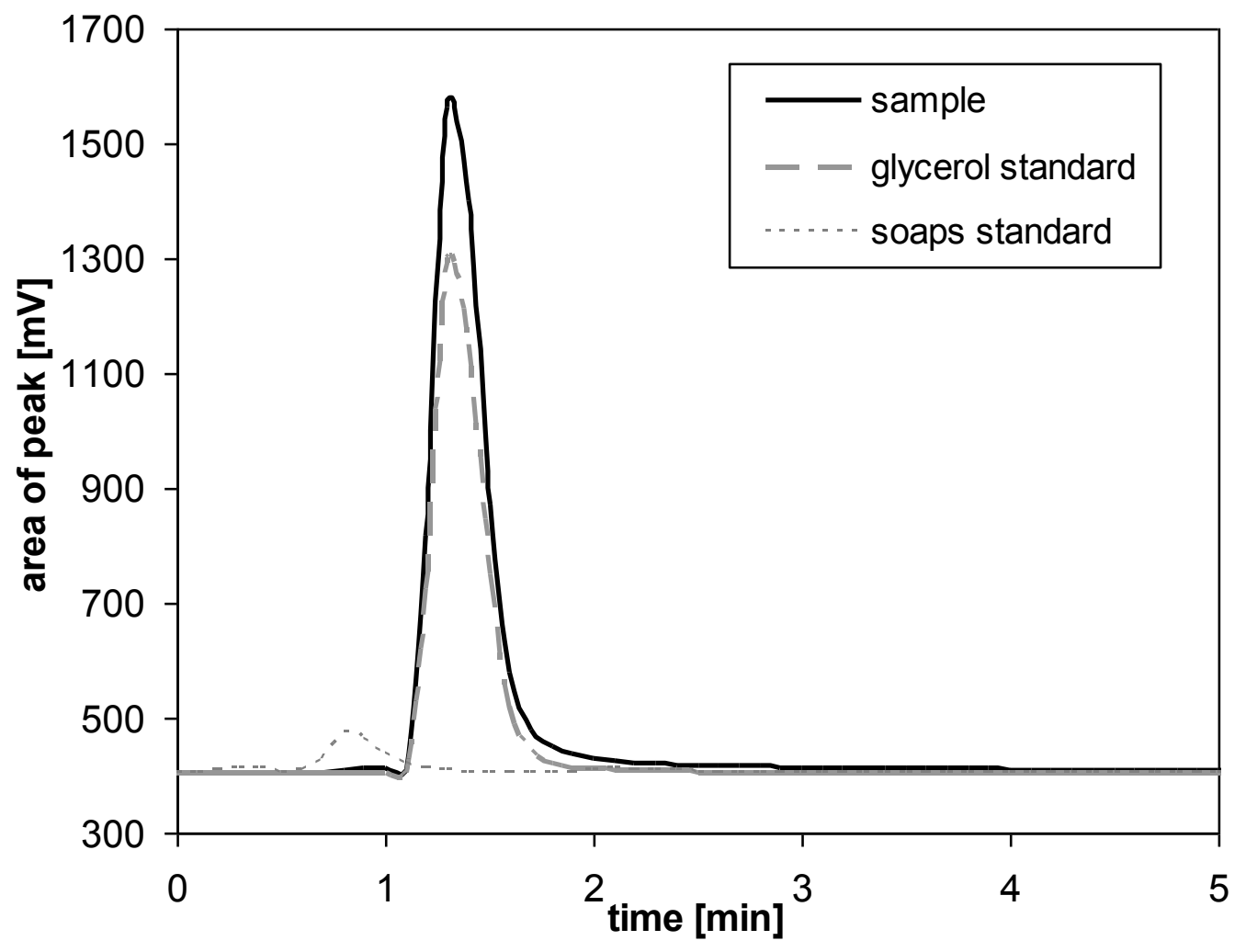

Fig. 2, Hájek 


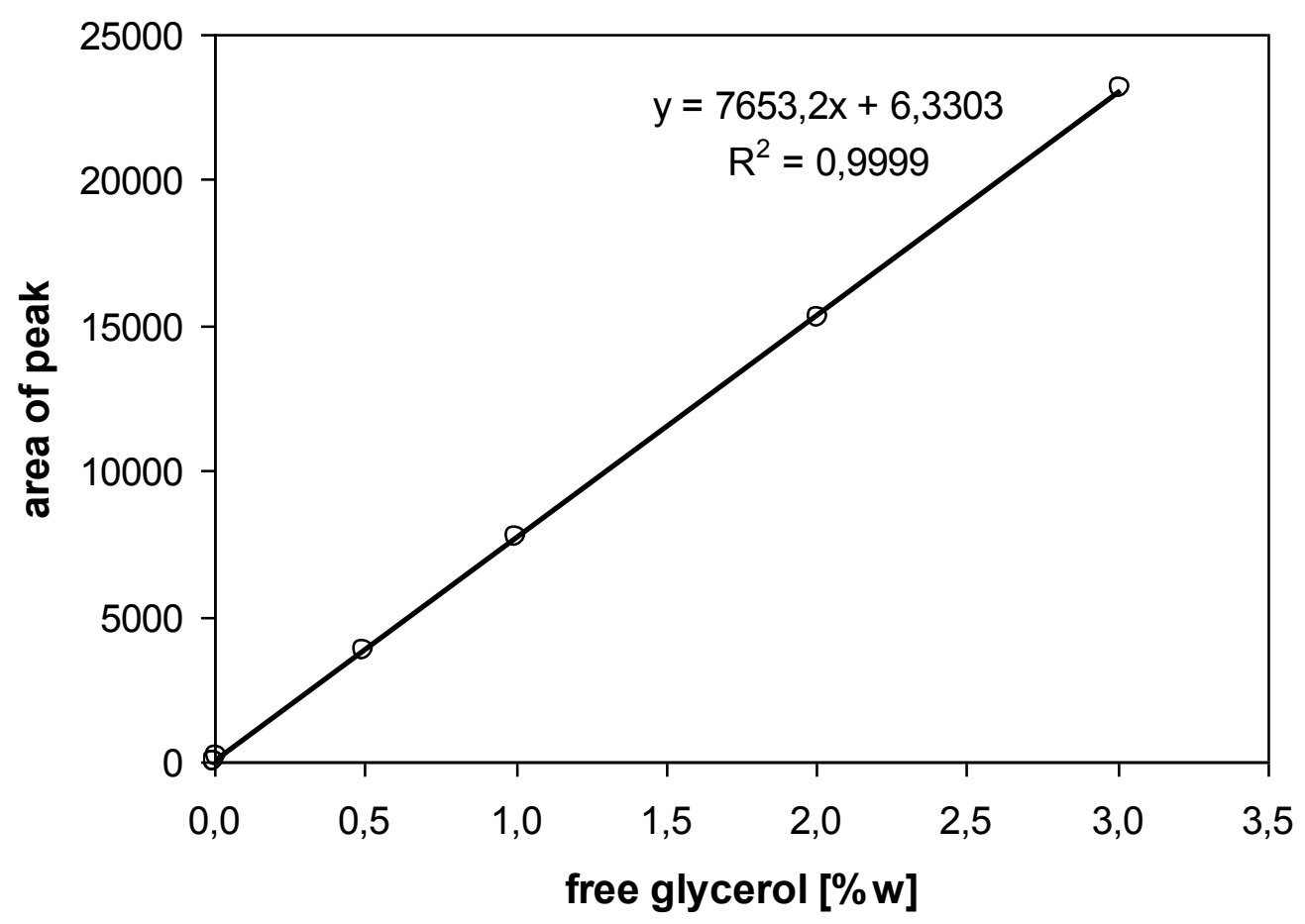

Fig. 3, Hájek 
Fig. 1 Apparatus for free glycerol extraction

Fig. 2 Identification of peaks in HPLC chromatogram of the aqueous glycerol concentrate

Fig. 3 Calibration curve for HPLC for determination of free glycerol concentration in biodiesel sample 
Tab. 1: Simulation of concentration process

\begin{tabular}{ccc}
\cline { 2 - 3 } & Given & Determined \\
\hline Concentration of free & 6.08 & $6.07 \pm 0.01$ \\
glycerol [w\%] & 1.77 & $1.71 \pm 0.03$ \\
& 0.68 & $0.64 \pm 0.00$ \\
\hline
\end{tabular}


Tab. 2: Concentration of free glycerol after in biodiesel after two steps

After $1^{\text {st }}$ extraction After $2^{\text {nd }}$ extraction

\begin{tabular}{ccc}
$\begin{array}{c}\text { Concentration of free } \\
\text { glycerol }[\mathrm{w} \%]\end{array}$ & $0.343 \pm 0.002$ & $0.0009 \pm 0.0001$ \\
& $0.343 \pm 0.002$ & $0.0007 \pm 0.0000$ \\
\hline
\end{tabular}


Tab. 3: Comparison of results obtained by GC and HPLC method for equally prepared aqueous glycerol concentrates

\begin{tabular}{ccc}
\hline Method & GC & HPLC \\
\hline & $0.139 \pm 0.002$ & $0.138 \pm 0.007$ \\
Concentration of free & $0.101 \pm 0.002$ & $0.096 \pm 0.005$ \\
glycerol [w\%] & $0.037 \pm 0.001$ & $0.038 \pm 0.002$ \\
& $0.013 \pm 0.000$ & $0.014 \pm 0.001$ \\
\hline
\end{tabular}

